\title{
Elevation of Dopamine Induced by Cigarette Smoking: Novel Insights from a [ " C]-(+)-PHNO PET Study in Humans
}

\author{
Bernard Le Foll*, I,2,3,4,5,6,7, Mihail Guranda', Alan A Wilson ${ }^{3,6,8}$, Sylvain Houle ${ }^{3,8}$, Pablo M Rusjan ${ }^{3,8}$, \\ Victoria C Wing', Laurie Zawertailo ${ }^{5,10,11}$, Usoa Busto ${ }^{10}$, Peter Selby ${ }^{4,6,10,11}$, Arthur L Brody ${ }^{12}$, \\ Tony P George P,7,9 and Isabelle Boileau $^{3,6,7,8,13}$
}

'Translational Addiction Research Laboratory, Centre for Addiction and Mental Health, Toronto, ON, Canada; ${ }^{2}$ Alcohol Research and Treatment Clinic, Addiction Medicine Services, Ambulatory Care and Structured Treatments, Centre for Addiction and Mental Health, Toronto, ON, Canada; ${ }^{3}$ Campbell Family Mental Health Research Institute, Centre for Addiction and Mental Health, Toronto, ON, Canada; ${ }^{4}$ Department of Family and Community Medicine, University of Toronto, Toronto, ON, Canada; ${ }^{5}$ Department of Pharmacology, University of Toronto, Toronto, ON, Canada; ${ }^{6}$ Department of Psychiatry, Division of Brain and Therapeutics, University of Toronto, Toronto, ON, Canada; ${ }^{7}$ Institute of Medical Sciences, University of Toronto, Toronto, ON, Canada; ${ }^{8}$ Research Imaging Centre, Centre for Addiction and Mental Health, Toronto, ON, Canada; ${ }^{9}$ Biobehavioural Addictions and Concurrent Disorders Laboratory (BACDRL), Centre for Addiction and Mental Health, Toronto, ON, Canada; ${ }^{10}$ Clinical Neuroscience Program, Centre for Addiction and Mental Health, Toronto, ON, Canada; "'Addiction Program, Centre for Addiction and Mental Health, Toronto, ON, Canada; ${ }^{12}$ Department of Psychiatry and Behavioral Sciences, University of California at Los Angeles (UCLA), Los Angeles, CA, USA; ${ }^{3}$ Addiction Imaging Research Group, Centre for Addiction and Mental Health, Toronto, ON, Canada

Positron emission tomography (PET) has convincingly provided in vivo evidence that psychoactive drugs increase dopamine (DA) levels in human brain, a feature thought critical to their reinforcing properties. Some controversy still exists concerning the role of DA in reinforcing smoking behavior and no study has explored whether smoking increases DA concentrations at the D3 receptor, speculated to have a role in nicotine's addictive potential. Here, we used PET and [ $\left.{ }^{\prime \prime} \mathrm{C}\right]-(+)-\mathrm{PHNO}\left(\left[{ }^{\prime \prime} \mathrm{C}\right]-(+)-4-\right.$ propyl-3,4,4a,5,6, I0bhexahydro-2H-naphtho[I,2-b][I,4]oxazin-9-ol) to test the hypothesis that smoking increases DA release $\left(\right.$ decreases $\left[{ }^{I I} \mathrm{C}\right]-(+)-\mathrm{PHNO}$ binding) in D2-rich striatum and D3-rich extra-striatal regions and is related to craving, withdrawal and smoking behavior. Ten participants underwent [ [ $\mathrm{C}]-(+)-\mathrm{PHNO}$ scans after overnight abstinence and after smoking a cigarette. Motivation to smoke (smoking topography), mood, and craving were recorded. Smoking significantly decreased self-reported craving, withdrawal, and [' $\mathrm{C}]-(+))-$ PHNO binding in D2 and D3-rich areas ( 12.0 and - 15.3\%, respectively). We found that motivation to smoke (puff rate) predicted magnitude of DA release in limbic striatum, and the latter was correlated with decreased craving and withdrawal symptoms. This is the first report suggesting that, in humans, DA release is increased in D3-rich areas in response to smoking. Results also support the preferential involvement of the limbic striatum in motivation to smoke, anticipation of pleasure from cigarettes and relief of withdrawal symptoms. We propose that due to the robust effect of smoking on [ ' $\mathrm{C}]-(+)-\mathrm{PHNO}$ binding, this radiotracer represents an ideal translational tool to investigate novel therapeutic strategies targeting DA transmission.

Neuropsychopharmacology (20 I4) 39, 4I5-424; doi:I0.1038/npp.2013.209; published online I8 September 20I3

Keywords: tobacco; PET; dopamine; ventral tegmental area; nicotine

\section{INTRODUCTION}

Most of our knowledge related to the role of dopamine (DA) in drug addiction comes from preclinical studies, but more recently positron emission tomography (PET) has allowed for the exploration of DA neurotransmission in vivo in humans. Psychostimulants drugs (such as amphetamine or

*Correspondence: Dr B Le Foll, Translational Addiction Research Laboratory, Campbell Family Mental Health Research Institute, Centre for Addiction and Mental Health (CAMH), 33 Russell Street, Toronto, Ontario, Canada M5S 2SI, Tel: +416 535 850I, ext. 4772, Fax: +4I6 595 6922, E-mail: bernard.lefoll@camh.ca

Received I4 February 2013; revised 23 July 2013; accepted 24 July 2013; accepted article preview online 19 August 2013 cocaine) that are known to produce massive elevation in dialysate DA levels (Di Chiara and Imperato, 1988) can induce euphoria in humans, and this effect is related to decreased radiotracer (eg: $\left[{ }^{11} \mathrm{C}\right]$-raclopride) binding interpreted as increased signaling at the D2/3 receptor (Laruelle, 2000; Laruelle et al, 1995; Volkow et al, 1999).

Unlike those psychostimulants, nicotine is known to produce relatively weak elevation in DA levels (Forget et al, 2010; Pontieri et al, 1996), which may explain why initial PET studies in animals report small, inconsistent changes in response to intravenous nicotine (Cumming et al, 2003; Marenco et al, 2004; Tsukada et al, 2002). Subsequently, in some studies smoking nicotine-containing cigarettes produced modest changes in $\left[{ }^{11} \mathrm{C}\right]$-raclopride binding in the 
limbic striatum (Brody et al, 2009; Brody et al, 2006; Brody et al, 2004; Domino et al, 2012; Domino et al, 2013) or in others, changes in $\left[{ }^{11} \mathrm{C}\right]$-raclopride binding were limited to those smokers finding the experience of nicotine/smoking pleasurable (Barrett et al, 2004; Montgomery et al, 2007). Elevations in extracellular DA induced by smoking have been associated to either craving (Brody et al, 2006; Brody et al, 2004), improved mood (Barrett et al, 2004; Brody et al, 2009; Montgomery et al, 2007) or greater puff volume (Brody et al, 2010). Therefore, the role of DA in nicotine addiction still remains unclear (refer to the study by Le Foll et al (2009a) for a review). While some authors agree that DA signaling at the D2/3 receptor appears to mediate the rewarding and motivational effects of nicotine, other have argued that DA may instead mediate aversion to acute nicotine or nicotine withdrawal (Grieder et al, 2012; Laviolette and Van Der Kooy, 2003a, b). Because of this complexity, it appears that the use of smoking topography to characterize smoking behavior may yield valuable insights, as rate of nicotine administration or latency to drug-use are critically related to drug reinforcements and warrants further study.

Although the bulk of human studies have focused indistinctively on the role of DA activity at the D2 and D3 receptor, different lines of evidence, mostly from preclinical work have shown that the D3 dopamine receptor may be particularly involved in nicotine addiction (Le Foll et al, 2007). D3 antagonism reduces the influence of cues on behavior using Pavlovian conditioning procedure (Le Foll et al, 2003), nicotine-induced place preferences (Le Foll et al, 2005; Pak et al, 2006), nicotine-induced reinstatement of nicotine seeking (Andreoli et al, 2003) and cue-induced reinstatement of nicotine seeking (Khaled et al, 2010). It is now possible to investigate DA occupancy at the D3 receptor using the PET probe $\left[{ }^{11} \mathrm{C}\right]-(+)$-PHNO (Wilson et al, 2005). Specifically, $\left[{ }^{11} \mathrm{C}\right]-(+)$-PHNO binding ( 20fold selectivity for D3 over D2) can be interpreted in a region-dependent manner, with binding in dorsal striatum (high D2/low D3 expression) more likely reflecting D2 receptor availability, and binding in hypothalamus and substantia nigra (SN) reflecting predominantly D3 availability. The ventral pallidum (VP) and globus pallidus (GP) are areas of mixed D2/D3 binding where the D3 fraction has been estimated to represent $75 \%$ and $65 \%$, respectively (Tziortzi et al, 2011). This agonist radioligand that allows measurement of D3 receptor binding also has greater sensitivity for detecting changes in DA levels compared with the antagonist radiotracer $\left[{ }^{19} \mathrm{C}\right]$-raclopride (Ginovart et al, 2006; Shotbolt et al, 2012). To date, no study has examined the effect of tobacco smoking on DA release in D3-rich extra-striatal areas or has investigated whether activity at this receptor accounts for motivation to smoke, craving, or mood (anxiety).

The aim of the study was to use PET/ $\left[{ }^{11} \mathrm{C}\right]-(+)-$ PHNO in human smokers to investigate whether smoking increases dopamine occupancy at the D2, as well as at the D3 receptor. We hypothesized that smoking a cigarette would decreases $\left[{ }^{11} \mathrm{C}\right]-(+)$-PHNO binding in the limbic and dorsal striatum as well as in $\mathrm{D}_{3}$-rich VP and $\mathrm{SN}$. We also predicted that smoking-induced DA release would be inversely correlated with subjective craving and anxiety ratings, and positively related to smoking behavior.
Individual differences in smoking behavior were investigated via smoking topography.

\section{MATERIALS AND METHODS}

\section{Subjects}

Participants between the ages of 19 and 45 were recruited using advertisements in the local newspapers and online postings. After phone screen, they came for an in-person assessment. Healthy smokers who smoked $\geqslant 10$ cigarettes a day excluding ultra-low nicotine cigarettes, who smoked for at least 2 years and scored $\geqslant 4$ on the Fagerström Test for Nicotine Dependence (FTND) (Heatherton et al, 1991) were enrolled. Eligible subjects did not meet criteria for substance abuse or dependence other than nicotine and caffeine at the time of the study and tested negative on broad-spectrum gas chromatography and mass spectroscopy urine drug toxicology screen. Exclusion criteria included pregnancy, claustrophobia, current psychoactive medication use, Axis I psychiatric disorders (other than nicotine dependence) as determined by the Mini International Neuropsychiatric Interview (MINI) (Sheehan et al, 1998), cardiovascular or cerebrovascular disease, history of neurological illness or head trauma, learning disabilities, and the presence of metallic implants.

\section{Smoking Topography}

Smoking topography measures the manner or intensity with which cigarettes are smoked and is postulated to be a measure of smoking reinforcement (Frederiksen et al, 1977). The Clinical Research Support System (CReSS from Borgwaldt KC, Richmond, VA), a widely used and reliable smoking topography system (Lee et al, 2003), was used to measure ad libitum smoking behavior of a single cigarette of the participant's own brand. Reported outcome measures are number of puffs, average and total puff volume, average puff duration and inter-puff interval. Subjects attended a separate study visit to familiarize themselves with the smoking topography device.

\section{Plasma Nicotine and Cotinine Determination}

A blood sample was taken prior to $\left[{ }^{11} \mathrm{C}\right]-(+)-\mathrm{PHNO}$ injection on both visits to determine nicotine and cotinine concentration $(\mathrm{ng} / \mathrm{ml})$ as in (Bernert et al, 1997).

\section{Scan Visits}

PET scans took place at least $24 \mathrm{~h}$ apart. Prior to each scan visit, the subjects were required to abstain for $\sim 12 \mathrm{~h}$ (overnight) from smoking and $24 \mathrm{~h}$ from alcohol, and limit their coffee consumption to one caffeinated drink on the day of the scan. Upon arrival at the lab, expired breath carbon monoxide (CO) (Micro III Smokerlyzer, Bedfont Instruments, Kent, England) and breath alcohol (Alco-sensor FST, Intoximeters, MO, USA) levels were measured to confirm abstinence from smoking and alcohol, respectively. CO values of $\geqslant 10 \mathrm{ppm}$ or any other than zero breath alcohol level identified failure to meet protocol requirements and led to scan cancellation. A urine sample 
was also collected to rule out use of drug of abuse and pregnancy. The subjects completed the baseline battery of craving scales-21-item nicotine-specific Visual Analog Scale (VAS; 100 point scale from agree to disagree), Questionnaire of Smoking Urges (QSU) (Tiffany and Drobes, 1991), abbreviated Tobacco Craving Questionnaire (TCQ) (Heishman et al, 2003), Urge to Smoke questionnaire (Jarvik et al, 2000), Minnesota Nicotine Withdrawal Scale (MNWS) (Hughes and Hatsukami, 1986), Beck Depression Inventory (BDI) (Beck and Steer, 1987), and State-Trait Anxiety Inventory (STAI) (Smith and Lay, 1974). Subjects were not aware of the condition assigned to the first scan visit (abstinence or smoking). They were taken to the negative pressure smoking room where they either smoked one cigarette (usual brand) via the smoking topography device or idled in the room for the similar amount time $(\sim 10 \mathrm{~min})$. Shortly after, subjects were placed in the PET scanner in the supine position and fitted with the thermoplastic head fixation system. After an intravenous line was placed in an antecubital vein, subjects completed the 'pre-scan' battery of questionnaires (TCQ, QSU, VAS, UTS, MNWS, STAI), and a blood sample of $6 \mathrm{ml}$ was collected for the measurement of plasma nicotine and metabolites levels. The average time between the smoking condition and radiotracer injection was $35.0 \pm 5.6 \mathrm{~min}$.

PET scans were performed using Siemens-Biograph HiRez XVI (Siemens Molecular Imaging, Knoxville, TN, USA.) PET/CT camera system, which measures radioactivity in 81 brain sections with a reconstructed pixel size of $1.07 \times 1.07 \times 2.00 \mathrm{~mm}$ each with an in-plane resolution of $5 \mathrm{~mm}$ full-width at half maximum (FWHM). A transmission scan was acquired and the emission scan, acquired in 32-bit list mode, began after bolus injection of $\left[{ }^{11} \mathrm{C}\right]-(+)$-PHNO (mean $\pm \mathrm{SD}$, dose: $9.9 \pm 1.1 \mathrm{mCi}$; specific activity: $1091.8 \pm 383.4 \mathrm{mCi} / \mu \mathrm{mol}$; mass: $2.3 \pm 0.7 \mu \mathrm{g}$; duration of the bolus injection $=2 \mathrm{~min}$ ). Emission data were reconstructed by $2 \mathrm{D}$ filtered back projection to yield dynamic images with 15 1-min frames and 15 5-min frames. The emission scan lasted for $90 \mathrm{~min}$. Upon scan completion, subjects were asked to complete the last, 'post-scan', questionnaire battery (TCQ, QSU, VAS, UTS, MNWS, STAI) and were discharged.

On a separate study visit to Toronto General Hospital, all subjects underwent a proton density weighted MRI scan acquired on a $1.5 \mathrm{~T}$ Signa GE scanner (slice thickness, $2 \mathrm{~mm}$; repetition time, $>5300 \mathrm{~ms}$; echo time, $13 \mathrm{~ms}$; flip angle, $90^{\circ}$; number of excitations, 2; acquisition matrix, $256 \times 256$; FOV, $22 \mathrm{~cm}$ ) for proper localization of regions of interest (ROIs).

\section{ROI Analysis}

Delineation of ROIs and time activity curve analyses for all subjects were performed using the automated image analysis software Regions of Mental Interest (ROMI) (Rusjan et al, 2006a). Functional striatal subcompartments, including sensorimotor striatum (SMST), associative striatum (AST), and limbic striatum (LST) were automatically segmented (Rusjan et al, 2006a) bilaterally as per the method described in (Martinez et al, 2003a). The globus pallidus (GP) delineation procedure used in this study was described elsewhere (Rusjan et al, 2006b); briefly, this method, which creates a probability map of gray matter voxels within the GP (in normal space), models on the procedural steps described in the study by Rusjan et al (2006a) with the exception that the segmentation algorithm (SPM2) focuses on classifying tissues in an area limited to GP, striatum and the surrounding white matter and uses the known volume of GP (3.7 cc; (Spinks et al, 2005)) as the targeted final volume of interest. Midbrain gray matter voxels within the substantia nigra (SN) region were identified using the automated procedure described in (Rusjan et al, 2006a). The boundaries of the ventral pallidum (VP) were cropped as in (Tziortzi et al, 2011). Cerebellar cortex (excluding vermis, lobules IX and $\mathrm{X}$ ) served as reference region. $\left[{ }^{11} \mathrm{C}\right]-(+)$-PHNO time activity curves were obtained from dynamic data, and specific binding $\left(\mathrm{BP}_{\mathrm{ND}}\right)$ was estimated in each ROI using the simplified reference tissue method (SRTM) (Lammertsma and Hume, 1996). Parameter estimation was performed with PMOD (Version 2.8.5; PMOD Technologies Ltd, Zurich, Switzerland).

\section{Voxel-Wise Parameter Estimation}

Voxel-wise parameter estimations of $\left[{ }^{11} \mathrm{C}\right]-(+)$-PHNO were generated using the basis function implementation of SRTM (Lammertsma and Hume, 1996), with the cerebellar cortex as reference region. Spatially normalized $\mathrm{BP}_{\mathrm{ND}}$ maps (SPM8; Wellcome Trust Centre for Neuroimaging, London, UK) were investigated statistically to assess significant contrasts conditions using paired $t$-test in SPM8. Only voxels having $\mathrm{BP}_{\mathrm{ND}}$ values of $>0.1$ were considered in the analysis. The threshold for significant clusters was set to a family-wise error (FWE) corrected at $P<0.05$.

\section{Statistical Analysis}

Differences in $\left[{ }^{11} \mathrm{C}\right]-(+)$-PHNO binding across ROIs between the conditions (abstinence and smoking) were analyzed using two-way repeated-measures analyses of variance (ANOVAs) (ROI $\times$ condition) with Bonferronicorrected post hoc comparisons (two-tailed, $\alpha=0.05$ ). Lateralization effect was explored using repeated-measures three-way ANOVA (ROI $\times$ condition $\times$ side). The effect of the order of treatment on the differences in binding between the conditions was explored with analysis of covariance (ANCOVA) using order of visits as a covariate. Greenhouse-Geisser adjustment was applied when the hypothesis of sphericity was rejected.

Scores on the self-reported questionnaire were analyzed using two-way repeated-measures ANOVA (condition $\times$ time) with Bonferroni-corrected pairwise comparisons (two-tailed, $\alpha=0.05$ ). Relationships between regional changes in $\left[{ }^{11} \mathrm{C}\right]-(+)-\mathrm{PHNO} \mathrm{BP}_{\mathrm{ND}}$ and other outcome measures (self-reported measures, plasma levels of nicotine and metabolites, smoking topography) were analyzed using the Pearson product moment correlation coefficient. To minimize the effect of anticipation all correlations were controlled for by order of visits. We also investigated whether D3 receptor levels $\left(\left[{ }^{11} \mathrm{C}\right]-(+)-\mathrm{PHNO} \mathrm{BP}_{\mathrm{ND}}\right.$ in substantia nigra in abstinence condition) predicted smoking behavior (Boileau et al, 2012; Boileau et al, 2013). Smoking-induced changes in self-reported measures were estimated by comparing changes in abstinence or smoking 
conditions between baseline and pre-scan (ABS is the abstinence scan, NIC is the smoking scan, and BSL is the baseline measure):

$\left(\mathrm{ABS}_{\mathrm{BSL}}-\mathrm{ABS}_{\mathrm{PRE}-\mathrm{SCAN}}\right)-\left(\mathrm{NIC}_{\mathrm{BSL}}-\mathrm{NIC}_{\text {PRE-SCAN }}\right)$

\section{RESULTS}

\section{Subject Characteristics}

Out of 19 subjects enrolled, we included a total of 10 subjects in the final analysis. One subject did not complete his MRI (VP was not delineated for this case as we did not have MRI guidelines). Three participants experienced nausea from $\left[{ }^{11} \mathrm{C}\right]-(+)$-PHNO injection and could not continue the scan, one person withdrew after the completion of the first PET scan, and others withdrew from the study prior to the first PET visit. Subject characteristics are described in Table 1. One participant tested positive for MDMA (ecstasy) on the abstinence condition (toxicology results were obtained after the completion of the scan) and later confirmed he used ecstasy 1 week prior to scan. His data were included in the analysis (no change were observed in the results while excluding this subject).

\section{Subjective Measures of Craving and Withdrawal}

Two-way repeated-measures ANOVA of craving and withdrawal scores indicated a significant condition by time interaction for self-reported 'urge to smoke for pleasurable effects' (TCQ 2/Expectancy $\mathrm{F}_{(2,18)}=7.7, P<0.005$ ), 'urge to smoke to relieve the negative affect' (QSU/Factor 2 $\mathrm{F}_{(2,18)}=6.9, \quad P<0.01 ; \quad$ TCQ $1 /$ emotionality $\quad \mathrm{F}_{(2,18)}=8.3$, $P<0.005)$ and overall urge to smoke (UTS, $\mathrm{F}_{(2,18)}=8.9$, $P<0.005)$. Specifically, the craving scores were significantly lower after smoking compared with same-day baseline level, whereas in abstinence condition the cravings did not significantly differ between the time points $P<0.05$; see Figure 1). Separate main effects of condition and time on 'anticipation of positive effects of smoking' (QSU Factor 1 $\mathrm{F}_{(1,9)}=13.172, P<0.01$ and $\mathrm{F}_{(2,18)}=8.585, P<0.005$, respectively) and 'intention to smoke' (TCQ 4/Purposefulness $\mathrm{F}_{(1,9)}=10.140, P<0.05$ and $\left.\mathrm{F}_{(2,18)}=4.622, P<0.05\right)$ were observed such that these measures were significantly lower during the smoking condition $(P<0.05)$ and reduced from same-day baseline $(P<0.05)$. Subjects reported less-pronounced withdrawal symptoms and anxiety under the smoking condition (main effect of condition for MNWS $\mathrm{F}_{(1,9)}=7.136, P<0.05$ and STAI $\left.\mathrm{F}_{(1,9)}=7.946, P<0.05\right)$; however, the interaction with time was marginally significant for withdrawal $(P=0.06)$ and non-significant for anxiety $(P=0.61$, respectively). Visual Analog Scale items'I have a craving for a cigarette' and 'I feel impatient'significantly changed over time (VAS7 $\mathrm{F}_{(2,18)}=10.07$, $P<0.005$; VAS10 $\mathrm{F}_{(2,18)}=4.715, P<0.05$, respectively), such that the subjects reported lower cravings and impatience after smoking a cigarette (Bonferroni-corrected, $P<0.05$ ). Baseline scores recorded during abstinence and smoking condition across all scales were not significantly different $(P$ corrected $>0.05$ ). Selected subjective craving measures are illustrated in Figure 1.
Table I Subject Characteristics $(n=10)$

\begin{tabular}{lcc}
\hline Characteristic & \multicolumn{2}{c}{$\%$} \\
\hline Sex & Female & 30 \\
& Male & 70 \\
& & \\
Race & Asian & 20 \\
& Caucasian & 40 \\
& Black & 20 \\
& Hispanic & 20 \\
& & \\
Age & Mean \pm SD \\
Years of education & $33.1 \pm 9.3$ \\
Cigarettes per day & $15.2 \pm 2.9$ \\
Fagerström Test for Nicotine & $13.2 \pm 3.2$ \\
Dependence (FTD) & $6.0 \pm 1.3$
\end{tabular}

Dependence (FTND)

Pack-years of cigarette smoking (as years*packs/day)

cO level (p.p.m.)

$10.9 \pm 7.6(4.0-25.0)$

$13.2 \pm 3.4$

\begin{tabular}{|c|c|c|c|}
\hline Beck Depression Inventory & $2.0 \pm 3.1$ & $2.8 \pm 3.7$ & 0.61 \\
\hline CO level at baseline (p.p.m.) & $4.6 \pm 2.5$ & $4.8 \pm 2.0$ & 0.81 \\
\hline $\begin{array}{l}\text { Time between smoking and scan } \\
\text { (min) }\end{array}$ & - & $35.0 \pm 5.6$ & - \\
\hline Total puff volume (ml) & - & $1023.2 \pm 699.3$ & - \\
\hline Number of puffs & - & $16.9 \pm 5.9$ & - \\
\hline Average puff volume (ml) & - & $57.8 \pm 20.6$ & 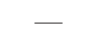 \\
\hline Puff duration (s) & - & $1.7 \pm 0.4$ & \\
\hline Plasma nicotine (ng/ml) & $2.5 \pm 2.3$ & $7.8 \pm 3.6$ & $0.001 *$ \\
\hline Plasma cotinine (ng/ml) & $128.5 \pm 96.4$ & $110.2 \pm 67.4$ & 0.40 \\
\hline Mass radioligand injected $(\mu \mathrm{g})$ & $2.5 \pm 0.7$ & $2.1 \pm 0.5$ & 0.2 \\
\hline Corrected activity (mCi) & $10.0 \pm 1.4$ & $9.8 \pm 0.9$ & 0.77 \\
\hline $\begin{array}{l}\text { Specific activity at time of injection } \\
(\mathrm{mCi} / \mu \mathrm{mol})\end{array}$ & $1009.8 \pm 304.1$ & $1173.8 \pm 450.5$ & 0.45 \\
\hline
\end{tabular}

Values are stated as mean $( \pm S D)$; $P$-values are for paired Student's $t$-tests between the abstinence and smoking conditions; $\mathrm{CO}$, exhaled carbon monoxide; p.p.m., parts per million.

*Statistically significant at a $* P<0.05$.

\section{PET $\left[{ }^{11} \mathrm{C}\right]-(+)-$ PHNO BP $\mathrm{ND}$}

Repeated-measures ANOVA of regional $\left[{ }^{11} \mathrm{C}\right]-(+)$-PHNO binding differences between the abstinence and smoking conditions yielded a significant condition $\times$ ROI interaction $\left(\mathrm{F}_{(1.8,14.7)}=4.6, P<0.05\right)$. Pairwise comparisons revealed significant decrease in $\left[{ }^{11} \mathrm{C}\right]-(+)-\mathrm{PHNO} \mathrm{BP}_{\mathrm{ND}}$ in LST (mean $\pm \mathrm{SD}) \quad(-12.0 \pm 8.8 \% ; n=10$, corrected $P<0.005$, Cohen's $d=0.86)$ and VP $(-15.3 \pm 15.7 \% ; n=9, P<0.05$, Cohen's $d=0.38$ ) under the smoking condition (Figure 2). These results were replicated by voxel-wise analysis (Figure 3). The reduction in binding potential was marginally significant in SMST $(-4.3 \pm 6.3 \%, P=0.06$, Cohen's $d=0.34)$ and did not reach statistical significance in SN $(-8.5 \pm 20 \%, \quad P=0.14, \quad$ Cohen's $d=0.42) \quad$ and AST $(-4.0 \pm 7.1 \% ; P=0.1$, Cohen's $d=0.27)$. Adding ROI laterality as a within-subject factor indicated significant 

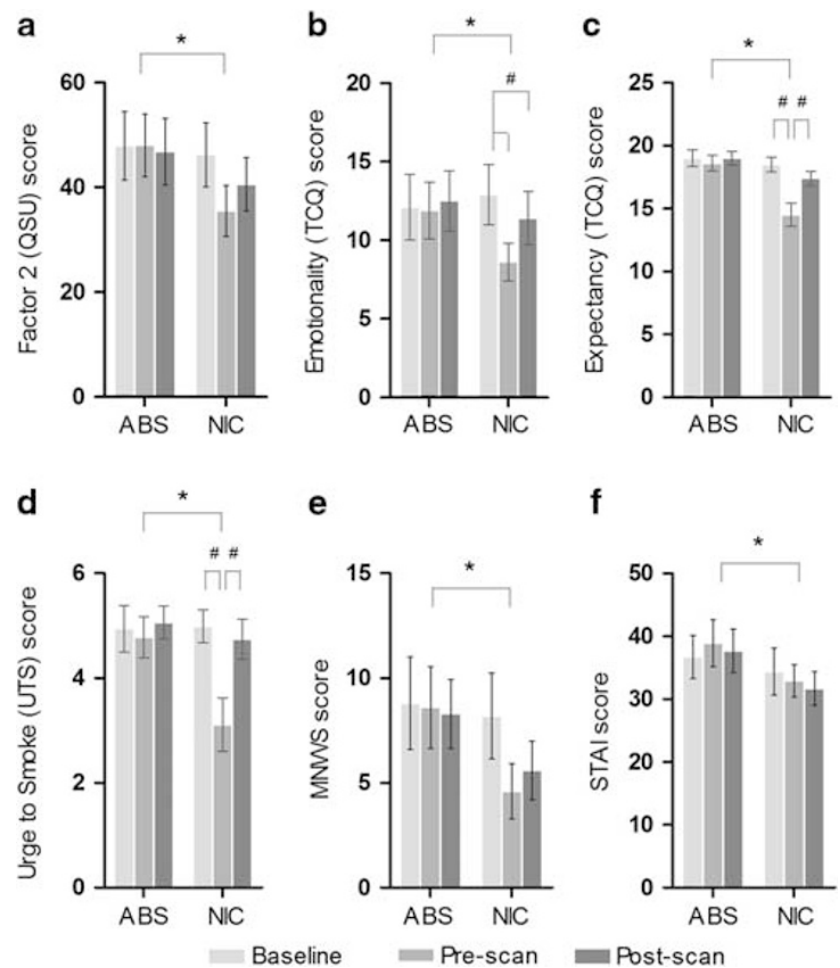

Figure I Subjective reports at baseline, pre- and post-scan time points in abstinence (ABS) and smoking (NIC) condition: (a). Factor 2 score (Questionnaire of Smoking Urges, QSU). (b). Emotionality factor (Tobacco Craving Questionnaire, TCQ. (c). Expectancy factor (Tobacco Craving Questionnaire, TCQ). (d). Urge to Smoke (UTS). (e). Minnesota Nicotine Withdrawal Scale (MNWS). (f). State-trait anxiety inventory (STAI). Mean \pm S.E.M.; * condition effect, $P<0.05$; ${ }^{*}$ pairwise Bonferroni-corrected comparison between the time points, $P<0.05$.

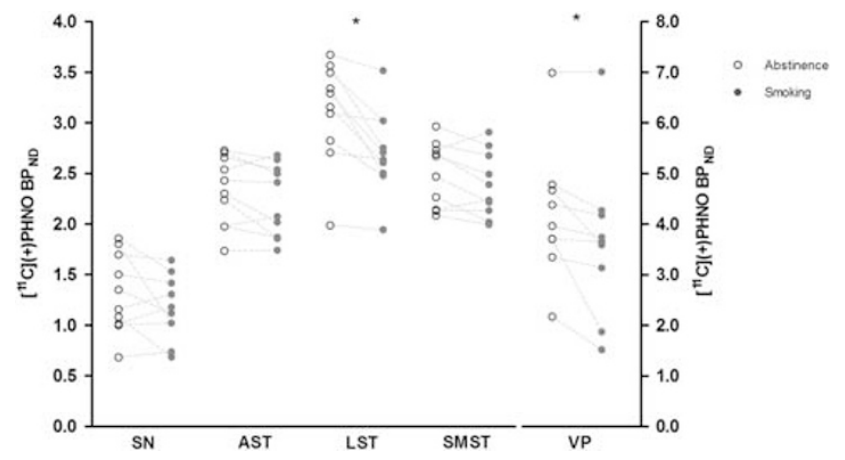

Figure $2\left[{ }^{\prime \prime} \mathrm{C}\right](+) \mathrm{PHNO} \mathrm{BP}_{\mathrm{ND}}$ in abstinence (empty circles) and smoking condition (full circles) in selected ROIs ( $n=10$, except for VP, $n=9$ ). Left y axis: SN, substantia nigra; AST, associative striatum; LST, limbic striatum; SMST, sensorimotor striatum; Right $y$ axis: VP, ventral pallidum; $* P<0.05$.

ROI $\times$ side interaction $\left(\mathrm{F}_{(2.2,17.9)}=7.034, P<0.01\right)$; however, no significant effect of side alone or its interaction with the condition effect was found. The condition $\times$ ROI interaction remained significant when ANCOVA with the order of treatment as a covariate was performed. Paired Student's $t$-test indicated a significant $\left[{ }^{11} \mathrm{C}\right]-(+)$-PHNO binding change in full striatum $(-6.3 \pm 5.3 \%, P<0.005)$. There was no difference in the area under the time activity curve for the cerebellum between the smoking and abstinence condition $(P=0.9)$.

We also analyzed data after excluding the subject who tested positive for MDMA on the abstinence condition. The 9 -subject sample changes in $\left[{ }^{11} \mathrm{C}\right]-(+)$-PHNO $\mathrm{BP}_{\mathrm{ND}}$ in LST $(-11.4 \pm 9.0 \% ; P<0.05)$ and VP $(-15.9 \pm 16.5 \% ; P<0.05)$ did not significantly differ from those of the 10-subject sample (unpaired Student's $t$-test, $P=0.88$ ).

\section{Correlation Analyses}

Decrease in $\left[{ }^{11} \mathrm{C}\right]-(+)$-PHNO binding in LST after smoking a cigarette was significantly associated with greater decrease in urge to smoke in anticipation of positive effects of smoking (TCQ 2/Expectancy, $\quad r=0.71 ; \quad P=0.03$ ), and marginally correlated with the urge to smoke to relieve the negative affect (QSU/Factor 2, $r=0.67 ; P<0.05)$ and overall urge to smoke (UTS, $r=0.67 ; P<0.05$ ). Subjects with greater smoking-induced decreases in LST $\left[{ }^{11} \mathrm{C}\right]-(+)-$ PHNO $\mathrm{BP}_{\mathrm{ND}}$ also consistently reported less withdrawal symptoms (MNWS, $r=0.73 ; P=0.03$ ) and anxiety on smoking condition (STAI, $r=0.76 ; P=0.02$ ). Greater number of puffs recorded during the smoking session significantly predicted lower LST $\left[{ }^{11} \mathrm{C}\right]-(+)$-PHNO $\mathrm{BP}_{\mathrm{ND}}$ $(r=-0.73, P$ uncorrected $=0.025)$ and was associated with the greater relief from nicotine withdrawal or negative affect with an urgent and overwhelming desire to smoke (QSU/ Factor $2 r=-0.71, P<0.05$ ) (Figure 4). In the D3-rich VP, we found the magnitude of $\left[{ }^{11} \mathrm{C}\right]-(+)$-PHNO displacement was related to reduced smoking-induced anxiety (STAI, $r=0.7 ; P=0.035$ ), but not reduced craving and withdrawal.

Plasma levels of nicotine and its metabolites showed no correlation with the changes in $\left[{ }^{11} \mathrm{C}\right]-(+)$-PHNO binding, subjective cravings and smoking behavior. $\mathrm{D}_{3}$ receptor levels (estimated in SN during abstinence) did not correlate with behavioral outcome measures and was not related to smoking-induced displacement.

\section{DISCUSSION}

To our knowledge, this is the first study to assess fluctuation of DA levels in $\mathrm{D}_{3}$ - and $\mathrm{D}_{2}$-rich areas in humans using $\left[{ }^{11} \mathrm{C}\right]$ (+)-PHNO. As expected, we found that smoking significantly attenuated craving and withdrawal scores induced by overnight abstinence. We also found that smoking had a robust effect on $\left[{ }^{11} \mathrm{C}\right]-(+)$-PHNO binding that could be detected in whole striatum, LST and D3-rich VP. Finally, we found that increased rate of smoking predicted $\left[{ }^{11} \mathrm{C}\right]-(+)-$ PHNO displacement in LST, which was related to decreased withdrawal symptoms and urge to smoke.

We were able to detect significant differences in binding potential between the two conditions. This effect was significant for the whole striatum, but more pronounced in LST and VP. The magnitude of the effect that has been exerted on $\left[{ }^{11} \mathrm{C}\right]-(+)$-PHNO binding by smoking appears of higher magnitude $(\sim 12 \pm 8.8 \%)$ than the effects previously reported using $\left[{ }^{11} \mathrm{C}\right]$-raclopride $(\sim 8 \pm 11.8 \%)$ (Brody et al, 2009). Although $\left[{ }^{11} \mathrm{C}\right]$-raclopride is perhaps the gold standard for measuring binding at $\mathrm{D}_{2 / 3}$ receptors, it has been proposed that $\left[{ }^{11} \mathrm{C}\right]-(+)$-PHNO may be superior to measure acute fluctuations in synaptic DA release 


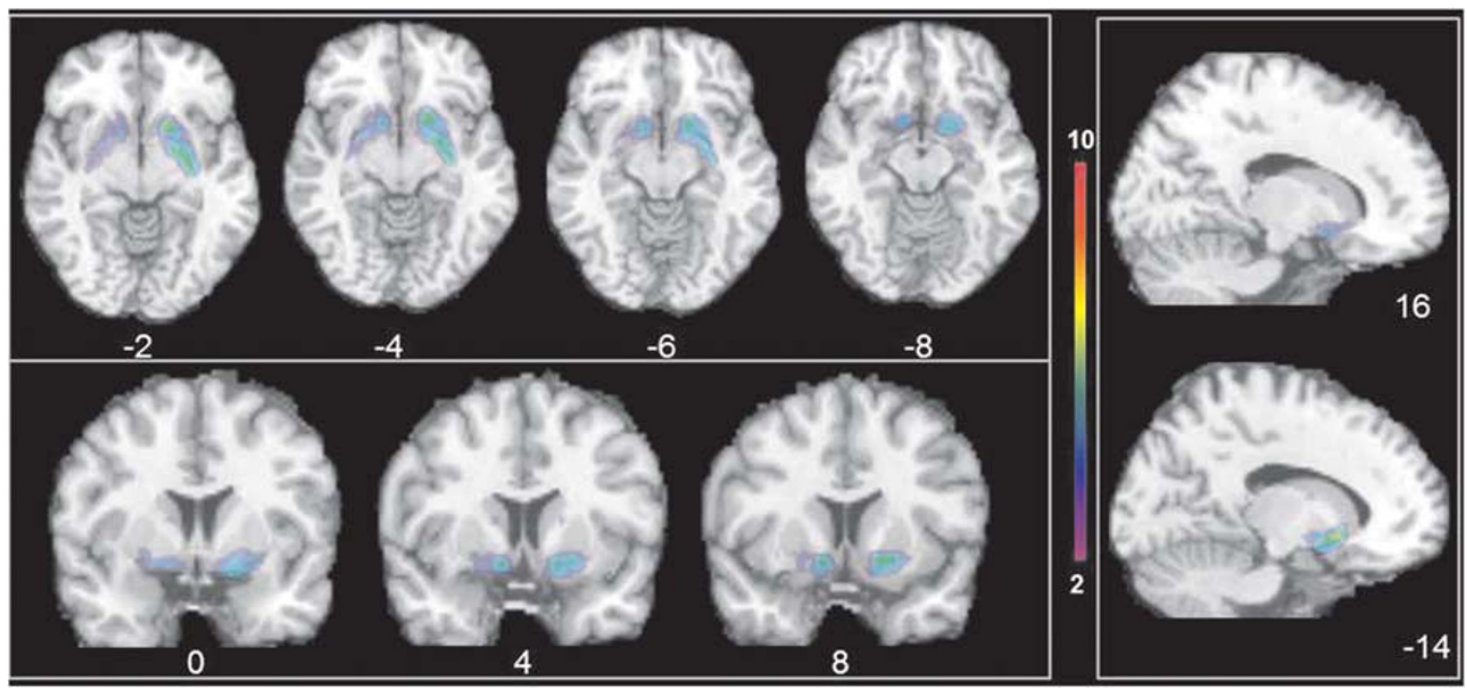

Figure 3 T-statistical overlaid average TI MRI showing clusters of significantly reduced [ [ $\mathrm{C}]$ - + - PHNO $\mathrm{BP}_{\mathrm{ND}}$ after smoking a cigarette. Greatest decreases in [ ' $\mathrm{C}]-+-\mathrm{PHNO} \mathrm{BP}_{\mathrm{ND}}$ cluster in the ventral part of the striatum and in the area that corresponds to the ventral pallidum $(\mathrm{t} \max =10.3 ; \mathrm{p} F W$-corrected $=0.03, k=736 ; x=-28, y=-10, z=-4$ ). For visualization purposes the image is threshold at a $P<0.05$ uncorrected.
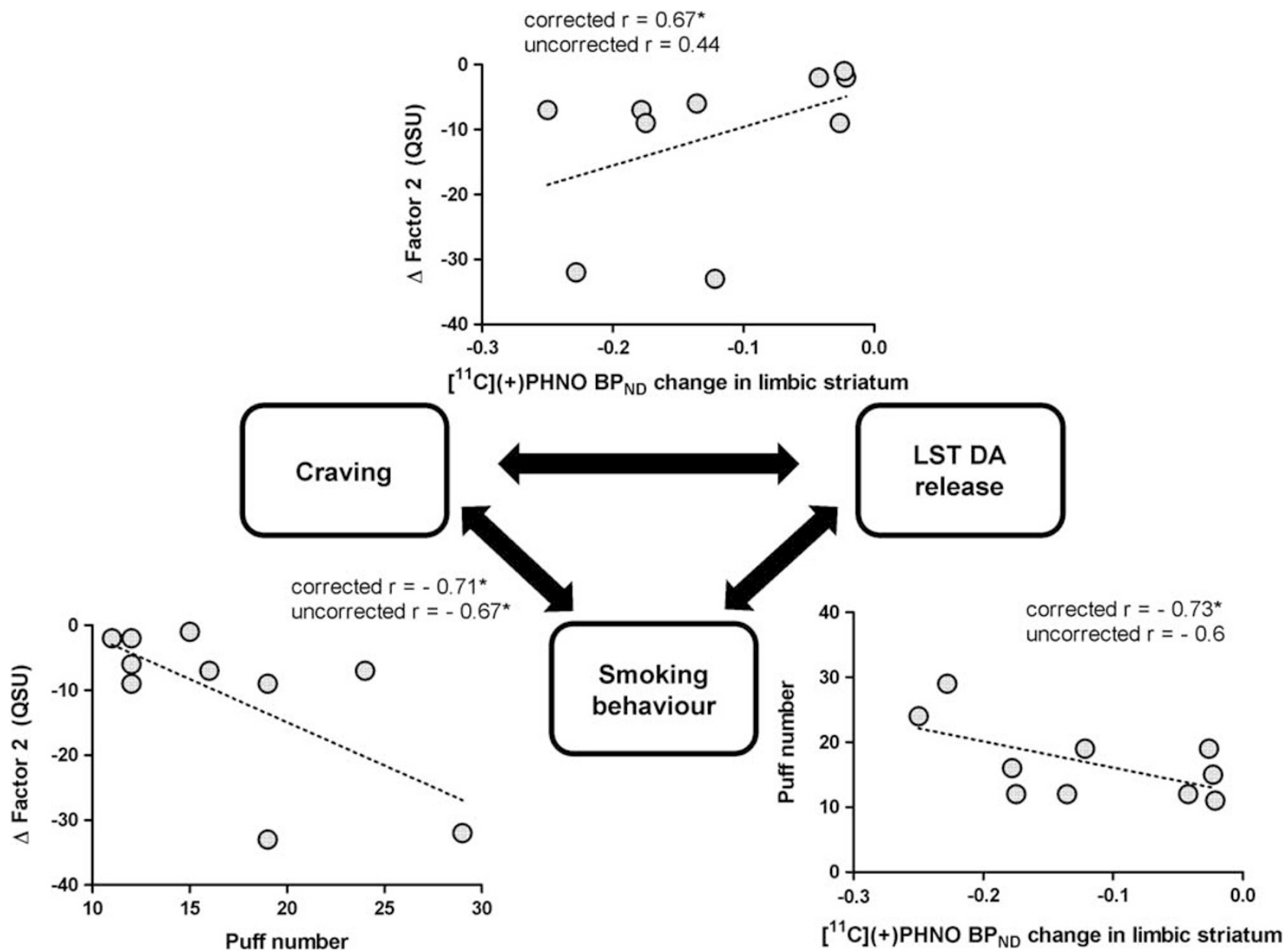

Figure 4 Relationship between [ I C $](+)$ PHNO BP ${ }_{\text {ND }}$ change in limbic striatum (LST), rate of smoking (puff number) and urge to smoke to relieve the negative affect (QSU/Factor 2; see in text for details on calculation). Pearson correlation coefficients (uncorrected $r$ ) and partial correlations coefficients (corrected $r$, controlling for the order of visits) are presented; $* P<0.05$. 
(Ginovart et al, 2006; Shotbolt et al, 2012). This higher sensitivity of $\left[{ }^{11} \mathrm{C}\right]-(+)$-PHNO over $\left[{ }^{11} \mathrm{C}\right]$-raclopride has also been recently confirmed in a recent study comparing the impact of nicotine and amphetamine on the binding of those two radiotracers in non-human primates (Gallezot et al, 2013). The first study conducted with smoking and $\left[{ }^{11} \mathrm{C}\right]$-raclopride PET found no overall significant displacement (Barrett et al, 2004). Subsequently, in a study that included 20 subjects, Brody et al (2004) observed a significant displacement with $\left[{ }^{11} \mathrm{C}\right]$-raclopride that appeared to have been found in LST, but also in the caudate and putamen. The magnitude of the DA release varied between the studies reported (Brody et al, 2004, 2006, 2009), but the largest study conducted so far with a sample of 46 subjects revealed an average decrease of $8.4 \pm 1.5 \%$ that can be detected following smoking a cigarette (Brody et al, 2009). Other groups have also reported that smoking a cigarette elicits DA release in the same range (Domino et al, 2012, 2013). In contrast to the radiotracer binding change previously observed in both ventral and dorsal striatum, our results with $\left[{ }^{11} \mathrm{C}\right]-(+)$-PHNO suggest that the ability of smoking to lead to DA release is most pronounced in LST with no significant effect in the AST and SMST.

Importantly, due to properties of the radiotracer employed, we report for the first time that smoking is able to elicit elevation of DA in the $\mathrm{D}_{3}$-rich VP and to a lesser extent in the SN where $100 \%$ of the binding is on $\mathrm{D}_{3}$ receptors. This indicates that smoking elevates DA levels in areas outside of the striatum. The fact that there is an increase of DA transmission at the level of $\mathrm{D}_{3}$ receptors give further validity to the hypothesis that blocking DA transmission at the level of $\mathrm{D}_{3}$ could be an effective strategy for nicotine addiction (Khaled et al, 2010; Le Foll et al, 2007). Further studies should explore the role of the ventral pallidum in drug addiction (Kemppainen et al, 2012) and notably the role of the $\mathrm{D}_{3}$ receptors (Le Foll et al, 2009a; Tziortzi et al, 2011) in this area.

One of the important findings of this study is the confirmation of a significant relationship between urge to smoke and elevation of DA in LST. Previous studies using $\left[{ }^{11} \mathrm{C}-\right]$-raclopride and smoking have linked smoking-induced DA release with hedonic response to cigarette smoking (Barrett et al, 2004), while studies with nicotine nasal spray found a correlation between nicotine-induced DA release and rating of happiness (Montgomery et al, 2007). The relationship between urge to smoke and smoking-induced DA release was found in one (Brody et al, 2004), but not all (Brody et al, 2009; Brody et al, 2006) studies where this question was examined. Here, using $\left[{ }^{11} \mathrm{C}\right]-(+)-\mathrm{PHNO}$, we found that only LST DA release was associated with the urge to smoke, whereas no correlation were found in other brain areas studied. This suggests that further studies should carefully analyze the different subregions of striatum when exploring such associations (Martinez et al, 2003b). Previously, a relationship between displacement of $\left[{ }^{11} \mathrm{C}\right.$-]-raclopride and mood, but not anxiety, was found in a relatively large study (Brody et al, 2009). Our study, in contrast, demonstrated a robust correlation between the subjective anxiety ratings and $\left[{ }^{11} \mathrm{C}\right]-(+)-$ PHNO displacement not only in LST, but also in VP. Some previous studies have suggested that there could be an inverse correlation between severity of nicotine dependence, as assessed with the Fagerström Test for Nicotine Dependence, and $\left[{ }^{11} \mathrm{C}\right.$-]-raclopride (Montgomery et al, 2007), although we did not observe such a relationship here, perhaps due to a limited sample size.

The exploratory correlational analysis revealed a strong relationship between withdrawal and increase in DA release. This previously unreported finding is of particular interest as numerous animal studies have suggested that the dysphoric effects associated with withdrawal could be DAmediated (Grieder et al, 2012), and this study provides evidence for such a relationship in humans. We also found that while the total puff volume correlated with the craving and not $\left[{ }^{11} \mathrm{C}\right]-(+)$-PHNO binding, the number of puffs subjects made during the smoking condition did correlate with both DA level elevation in LST and decrease in urge to smoke. This is in agreement with previous studies (Williams et al, 2011) where rate of smoking has been shown to be related to withdrawal symptoms attenuation. Lastly, we found no correlation between the $\left[{ }^{11} \mathrm{C}\right]-(+)$-PHNO displacement and plasma nicotine levels, in contrast with the study by Domino et al (2013), which showed an increase in venous plasma nicotine concentrations to be correlated with increased DA release in the left caudate nucleus. This could be explained by modest rise in nicotine levels $(7.8 \pm 3.6 \mathrm{ng} / \mathrm{ml})$ obtained through controlled smoking compared with smoking to 'satiation' paradigm where nicotine levels achieve $30 \mathrm{ng} / \mathrm{ml}$ in $30 \mathrm{~min}$ (Sacco et al, 2005).

Our study has some limitations. First of all, the sample size was modest, raising the question of power. While we were powered enough to observe DA release in LST (Cohen's $d=0.86$ ), lack of significant findings in AST and marginally significant DA release in SMST could be due to small effect size (Cohen's $d=0.27$ and 0.34, for AST and SMST respectively). Furthermore, it is possible that smaller smoking-induced changes in $\left[{ }^{11} \mathrm{C}\right]-(+)$-PHNO in dorsal striatum are potentially due to a lower displacement sensitivity in areas of minimal DRD3 fraction. However, in a recent study the bindings of both $\left[{ }^{11} \mathrm{C}\right]-(+)$-PHNO and $\left[{ }^{11} \mathrm{C}\right]$-raclopride were affected in the same brain areas in non-human primates following nicotine and amphetamine administration (Gallezot et al, 2013). The small sample size did not allow us to explore the gender differences or additional factors, such as gene variants, that could underlie inter-individual variability (Brody et al, 2006; Domino et al, 2012). Finally, as the significance level of the exploratory correlations between the DA release, withdrawal and smoking behavior was not corrected for multiple comparisons, these finding could be due to type I error.

We also acknowledge some design-related limitations. Owing to the institution policy, subjects were unable to smoke in the scanner; hence, smoking took place in a separate area. This led to relatively long break between cigarette smoking and radiotracer injection $(35 \mathrm{~min}$, on average), possibly preventing us from observing correlations between the plasma nicotine concentration and striatal DA release. The time between the cigarette smoke and the end of PET scanning was around 2 hours, a period that may not have been ideal to measure elevation of dopamine induced by smoking. However, we do not believe it was an issue. Indeed, microdialysis experiments performed in non-human primates or rodents indicate that elevation of dopamine are almost at maximal level at the 
time-point we selected for the beginning of the scanning time, and elevation of dopamine are prolonged and can last at least 2 hours in some reports (Domino and Tsukada, 2009; Forget et al, 2009). We also did not use denicotinized cigarette as a control. Although we believe that comparing abstinence and smoking conditions is of clinical relevance, the current design could not dissociate the role of the substances other than nicotine that are present in tobacco smoke that could modulate the reinforcing effects of nicotine or the role of conditioning factors that are thought to be critically involved in the reinforcing properties of nicotine (Le Foll and Goldberg, 2009b). The fact that administration of nicotine through nicotine spray failed to produce a significant displacement of $\left[{ }^{11} \mathrm{C}\right]$-raclopride (Montgomery et al, 2007) suggests that conditioning factors could be important. It is noteworthy that in a recent study, presentation of smoking-associated cues was not able to affect $\left[{ }^{11} \mathrm{C}\right]-(+)$-PHNO binding while the subjects were under the influence of nicotine (Chiuccariello et al, 2013), suggesting that at early abstinence, nicotine is more potent than cues to elicit dopamine release in human smokers. The ability of smoking cues to elicit dopamine release should be explored at a longer abstinence period in future studies. The fact that denicotinized cigarettes did not affect $\left[{ }^{11} \mathrm{C}\right]$ raclopride binding indicates that nicotine is central to smoking-induced DA release (Brody et al, 2009).

A group of methodological caveats are related to the PET imaging acquisition and analysis procedures. The injected mass of the radiotracer in our study slightly exceed the the mass limit suggested by Gallezot et al (2012), potentially leading to underestimation of dopamine occupancy in both conditions (Shotbolt et al, 2012). The injected mass, however, did not differ between the groups and did not correlate with $\left[{ }^{11} \mathrm{C}\right]-(+)-\mathrm{PHNO} \mathrm{BP}_{\mathrm{ND}}$. In addition, as the injected mass was on average higher in the abstinence $v s$ smoking conditions $(0.031 \pm 0.011 \mu \mathrm{g} / \mathrm{kg} v s 0.026 \pm 0.008 \mu \mathrm{g} /$ $\mathrm{kg}$ ), the injected mass could not account for the lowest binding of $\left[{ }^{11} \mathrm{C}\right]-(+)$-PHNO observed in the smoking condition. Moreover, the study findings are limited by the SRTM assumption of no specific binding in the cerebellum. This assumption is likely to be met, as the cerebellar standard uptake values did not differ between the conditions. Finally, although the test-retest scan reliability study for $\left[{ }^{11} \mathrm{C}\right]-(+)-\mathrm{PHNO}$ did not show significant differences in any of the ROIs (Willeit et al, 2006), data on the reliability of smoking-induced $\left[{ }^{11} \mathrm{C}\right]-(+)$-PHNO occupancy quantification are not available yet.

In conclusion, this study demonstrated that we can detect significant differences in limbic striatum and ventral pallidum DA levels induced by smoking (compared with abstinence) using $\left[{ }^{11} \mathrm{C}\right]-(+)$-PHNO. We found significant correlations between elevation of DA in the limbic striatum and decreases of withdrawal, urge to smoke, and anxiety ratings. Another innovative aspect of this study is the observed correlation between DA release in limbic striatum and ventral pallidum and decrease in anxiety. This study also demonstrate that there is an increase of DA transmission at the level of D3 receptors supporting the hypothesis that blocking D3 transmission could have therapeutic value for nicotine addiction. Owing to the robust and significant effects obtained with $\left[{ }^{11} \mathrm{C}\right]-(+)$-PHNO to detect smokinginduced DA release, we propose that this radiotracer may represent a useful tool for the assessment of novel therapeutic strategies that could modulate smoking-induced DA release and to study the impact of smoking in different populations of smokers.

\section{FUNDING AND DISCLOSURE}

Dr Guranda, Dr Wilson, Dr Houle, Dr Rusjan, Dr Busto and Dr Boileau declare no potential conflict of interest. Dr Le Foll has received grant and salary support from Pfizer Inc. and is a consultant for Richter Pharmaceuticals, Lundbeck, Mylan, Ethypharm and Pfizer. Dr Wing has received funding from the Pfizer Global Research Awards in Nicotine Dependence (GRAND) and the Pfizer Investigated Initiated Research (IIR) schemes and from the Canadian Institute of Health Research (CIHR) and the Ontario Mental Health Foundation (OMHF). Dr Zawertailo reports no conflict of interest in regards to this work. Dr Zawertailo has received grant funding from the Canadian Institutes of Health Research (CIHR), the Ontario Lung Association (OLA), Cancer Care Ontario, the Canadian Tobacco Control Research Initiative (CTCRI), the Global Research Awards for Nicotine Dependence (GRAND) and Pfizer Canada, and has received travel funds from Pfizer Canada. She has served as a paid expert witness for Avanir Pharmaceuticals. Dr Selby has no competing interests to declare with respect to this manuscript. Dr Selby has received research support from Pfizer including the Grand Award, Ministry of Health and Long term Care Ontario, Canadian Institutes of Health Research, Public Health Agency of Canada, and Health Canada; and, consulting or speaker fees from AbbVie, Pfizer Canada, Mylan pharmaceuticals and NABI pharmaceuticals. He has no personal financial interests. Dr Brody has nothing to disclose. Dr Brody's work has been funded by the National Institute on Drug Abuse (A.L.B. [R01 DA20872]), the Tobacco-Related Disease Research Program (A.L.B. [19XT-0135]), and the Department of Veterans Affairs, Office of Research and Development (CSR\&D Merit Review Award I01 CX000412 (A.L.B.)). Dr George has received consulting fees from Pfizer and Novartis, and grant/contract support from Pfizer, the National Institutes of Health, the Canada Foundation for Innovation, the Canadian Institutes of Health Research and the Ontario Mental Health Foundation.

\section{ACKNOWLEDGEMENTS}

We would like to acknowledge the support of Research Imaging Center staff. This study was supported in part by a 2010 Pfizer GRAND Award awarded to Dr Le Foll and Canadian Foundation for Innovation.

\section{REFERENCES}

Andreoli M, Tessari M, Pilla M, Valerio E, Hagan JJ, Heidbreder CA (2003). Selective antagonism at dopamine D3 receptors prevents nicotine-triggered relapse to nicotine-seeking behavior. Neuropsychopharmacology 28: 1272-1280.

Barrett SP, Boileau I, Okker J, Pihl RO, Dagher A (2004). The hedonic response to cigarette smoking is proportional to dopamine release in the human striatum as measured by positron emission tomography and [11C]raclopride. Synapse 54: 65-71. 
Beck AT, Steer RA (1997). Beck Depression Inventory. Center for Cognitive Therapy: Philadelphia, PA, USA.

Bernert JT Jr., Turner WE, Pirkle JL, Sosnoff CS, Akins JR, Waldrep MK et al (1997). Development and validation of sensitive method for determination of serum cotinine in smokers and nonsmokers by liquid chromatography/atmospheric pressure ionization tandem mass spectrometry. Clin Chem 43: 2281-2291.

Boileau I, Payer D, Houle S, Behzadi A, Rusjan PM, Tong J et al (2012). Higher binding of the dopamine D3 receptor-preferring ligand [11C]-(+)-propyl-hexahydro-naphtho-oxazin in methamphetamine polydrug users: a positron emission tomography study. J Neurosci 32: 1353-1359.

Boileau I, Payer D, Chugani B, Lobo D, Behzadi A, Rusjan PM et al (2013). The $\mathrm{D}(2 / 3)$ dopamine receptor in pathological gambling: a positron emission tomography study with $[(11) \mathrm{C}]-(+)-$ propyl-hexahydro-naphtho-oxazin and [(11) C]raclopride. Addiction 108: 953-963.

Brody AL, London ED, Olmstead RE, Allen-Martinez Z, Shulenberger S, Costello MR et al (2010). Smoking-induced change in intrasynaptic dopamine concentration: effect of treatment for tobacco dependence. Psychiatry Res 183: 218-224.

Brody AL, Mandelkern MA, Olmstead RE, Allen-Martinez Z, Scheibal D, Abrams AL et al (2009). Ventral striatal dopamine release in response to smoking a regular vs a denicotinized cigarette. Neuropsychopharmacology 34: 282-289.

Brody AL, Mandelkern MA, Olmstead RE, Scheibal D, Hahn E, Shiraga S et al (2006). Gene variants of brain dopamine pathways and smoking-induced dopamine release in the ventral caudate/nucleus accumbens. Arch Gen Psychiatry 63: 808-816.

Brody AL, Olmstead RE, London ED, Farahi J, Meyer JH, Grossman $\mathrm{P}$ et al (2004). Smoking-induced ventral striatum dopamine release. Am J Psychiatry 161: 1211-1218.

Chiuccariello L, Boileau I, Guranda M, Rusjan PM, Wilson AA, Zawertailo L et al (2013). Presentation of smoking-associated cues does not elicit dopamine release after one-hour smoking abstinence: a [(11)C]-(+)-PHNO PET study. PLoS One 8: e60382.

Cumming P, Rosa-Neto P, Watanabe H, Smith D, Bender D, Clarke PB et al (2003). Effects of acute nicotine on hemodynamics and binding of [11C]raclopride to dopamine D2,3 receptors in pig brain. Neuroimage 19: 1127-1136.

Di Chiara G, Imperato A (1988). Drugs abused by humans preferentially increase synaptic dopamine concentrations in the mesolimbic system of freely moving rats. Proc Natl Acad Sci USA 85: 5274.

Domino EF, Evans CL, Ni L, Guthrie SK, Koeppe RA, Zubieta JK (2012). Tobacco smoking produces greater striatal dopamine release in G-allele carriers with mu opioid receptor A118G polymorphism. Prog Neuropsychopharmacol Biol Psychiatry 38: 236-240.

Domino EF, Ni L, Domino JS, Yang W, Evans C, Guthrie S et al (2013). Denicotinized versus average nicotine tobacco cigarette smoking differentially releases striatal dopamine. Nicotine Tob Res 15: 11-21.

Domino EF, Tsukada H (2009). Nicotine sensitization of monkey striatal dopamine release. Eur J Pharmacol 607: 91-95.

Forget B, Hamon M, Thiebot MH (2009). Involvement of alpha1adrenoceptors in conditioned place preference supported by nicotine in rats. Psychopharmacology (Berl) 205: 503-515.

Forget B, Wertheim C, Mascia P, Pushparaj A, Goldberg SR, Le Foll B (2010). Noradrenergic alphal receptors as a novel target for the treatment of nicotine addiction. Neuropsychopharmacology 35: $1751-1760$.

Frederiksen LW, Miller PM, Peterson GL (1977). Topographical components of smoking behavior. Addict Behav 2: 55-61.

Gallezot J-D, Kloczynski T, Weinzimmer D, Labaree D, Zheng M-Q, Lim $\mathrm{K}$ et al (2013). Imaging nicotine- and amphetamine-induced dopamine release in rhesus monkeys with [11C]PHNO versus
[11C]raclopride PET. Neuropsychopharmacology (e-pub ahead of print).

Gallezot JD, Beaver JD, Gunn RN, Nabulsi N, Weinzimmer D, Singhal $\mathrm{T}$ et al (2012). Affinity and selectivity of [(1)(1)C]-(+)PHNO for the D3 and D2 receptors in the rhesus monkey brain in vivo. Synapse 66: 489-500.

Ginovart N, Galineau L, Willeit M, Mizrahi R, Bloomfield PM, Seeman $\mathrm{P}$ et al (2006). Binding characteristics and sensitivity to endogenous dopamine of [11C]- $(+)-$ PHNO, a new agonist radiotracer for imaging the high-affinity state of D2 receptors in vivo using positron emission tomography. J Neurochem 97: 1089-1103.

Grieder TE, George O, Tan H, George SR, Le Foll B, Laviolette SR et al (2012). Phasic D1 and tonic D2 dopamine receptor signaling double dissociate the motivational effects of acute nicotine and chronic nicotine withdrawal. Proc Natl Acad Sci USA 109: 3101-3106.

Heatherton TF, Kozlowski LT, Frecker RC, Fagerstrom KO (1991). The Fagerstrom test for nicotine dependence: a revision of the Fagerstrom tolerance questionnaire. Br J Addict 86: 1119-1127.

Heishman SJ, Singleton EG, Moolchan ET (2003). Tobacco craving questionnaire: reliability and validity of a new multifactorial instrument. Nicotine Tob Res 5: 645-654.

Hughes JR, Hatsukami D (1986). Signs and symptoms of tobacco withdrawal. Arch Gen Psychiatry 43: 289-294.

Jarvik ME, Madsen DC, Olmstead RE, Iwamoto-Schaap PN, Elins JL, Benowitz NL (2000). Nicotine blood levels and subjective craving for cigarettes. Pharmacol Biochem Behav 66: 553-558.

Kemppainen H, Raivio N, Suo-Yrjo V, Kiianmaa K (2012). Opioidergic modulation of ethanol self-administration in the ventral pallidum. Alcohol Clin Exp Res 36: 286-293.

Khaled MA, Farid Araki K, Li B, Coen KM, Marinelli PW, Varga J et al (2010). The selective dopamine D3 receptor antagonist SB 277011-A, but not the partial agonist BP 897, blocks cue-induced reinstatement of nicotine-seeking. Int J Neuropsychopharmacology 13: 181-190.

Lammertsma AA, Hume SP (1996). Simplified reference tissue model for PET receptor studies. Neuroimage 4(3 Pt 1): 153-158.

Laruelle M (2000). Imaging synaptic neurotransmission with in vivo binding competition techniques: a critical review. J Cereb Blood Flow Metab 20: 423-451.

Laruelle M, Abi-Dargham A, van Dyck CH, Rosenblatt W, ZeaPonce Y, Zoghbi SS et al (1995). SPECT imaging of striatal dopamine release after amphetamine challenge. J Nucl Med 36: $1182-1190$.

Laviolette SR, Van Der Kooy D (2003a). Blockade of mesolimbic dopamine transmission dramatically increases sensitivity to the rewarding effects of nicotine in the ventral tegmental area. $\mathrm{Mol}$ Psychiatry 8: 50-59.

Laviolette SR, Van Der Kooy D (2003b). The motivational valence of nicotine in the rat ventral tegmental area is switched from rewarding to aversive following blockade of the alpha7-subunitcontaining nicotinic acetylcholine receptor. Psychopharmacology (Berl) 166: 306-313.

Le Foll B, Gallo A, Le Strat Y, Lu L, Gorwood P (2009a). Genetics of dopamine receptors and drug addiction: a comprehensive review. Behav Pharmacol 20: 1-17.

Le Foll B, Goldberg SR (2009b). Effects of nicotine in experimental animals and humans: an update on addictive properties. Handbook of Experimental Pharmacology 192: 335-367.

Le Foll B, Goldberg SR, Sokoloff P (2007). Dopamine D3 receptor ligands for the treatment of tobacco dependence. Expert Opin Invest Drug 16: 45-57.

Le Foll B, Schwartz J-C, Sokoloff P (2003). Disruption of nicotine conditioning by dopamine D3 receptor ligands. Mol Psychiatry 8: $225-230$.

Le Foll B, Sokoloff P, Stark H, Goldberg SR (2005). Dopamine D3 ligands block nicotine-induced conditioned place preferences 
through a mechanism that does not involve discriminativestimulus or antidepressant-like effects. Neuropsychopharmacology 30: 720-730.

Lee EM, Malson JL, Waters AJ, Moolchan ET, Pickworth WB (2003). Smoking topography: reliability and validity in dependent smokers. Nicotine Tob Res 5: 673-679.

Marenco S, Carson RE, Berman KF, Herscovitch P, Weinberger DR (2004). Nicotine-induced dopamine release in primates measured with [11C]raclopride PET. Neuropsychopharmacology 29: 259-268.

Martinez D, Slifstein M, Broft A, Mawlawi O, Hwang DR, Huang Y et al (2003a). Imaging human mesolimbic dopamine transmission with positron emission tomography. Part II: amphetamineinduced dopamine release in the functional subdivisions of the striatum. J Cereb Blood Flow Metab 23: 285.

Martinez D, Slifstein M, Broft A, Mawlawi O, Hwang DR, Huang Y et al (2003b). Imaging human mesolimbic dopamine transmission with positron emission tomography. Part II: amphetamine-induced dopamine release in the functional subdivisions of the striatum. J Cereb Blood Flow Metab 23: 285-300.

Montgomery AJ, Lingford-Hughes AR, Egerton A, Nutt DJ, Grasby PM (2007). The effect of nicotine on striatal dopamine release in man: A [11C]raclopride PET study. Synapse 61: 637-645.

Pak AC, Ashby CR Jr., Heidbreder CA, Pilla M, Gilbert J, Xi ZX et al (2006). The selective dopamine D3 receptor antagonist SB$277011 \mathrm{~A}$ reduces nicotine-enhanced brain reward and nicotinepaired environmental cue functions. Int J Neuropsychopharmacol 9: 585-602.

Pontieri FE, Tanda G, Orzi F, Di Chiara G (1996). Effects of nicotine on the nucleus accumbens and similarity to those of addictive drugs. Nature 382: 255-257.

Rusjan P, Mamo D, Ginovart N, Hussey D, Vitcu I, Yasuno F et al (2006a). An automated method for the extraction of regional data from PET images. Psychiatry Res 147: 79-89.

Rusjan PM, Mizrahi R, Ginovart N, Graff A, Willeit M, Vitcu I et al (2006b). Validation of a method for automatic quantification of radioactivity in the globus pallidus in $[11 \mathrm{C}]-(+)$-PHNO PET images. NeuroImage 31: T96.

Sacco KA, Termine A, Seyal A, Dudas MM, Vessicchio JC, Krishnan-Sarin S et al (2005). Effects of cigarette smoking on spatial working memory and attentional deficits in schizophrenia: involvement of nicotinic receptor mechanisms. Arch Gen Psychiatry 62: 649-659.
Sheehan DV, Lecrubier Y, Sheehan KH, Amorim P, Janavs J, Weiller E et al (1998). The Mini-International Neuropsychiatric Interview (M.I.N.I.): the development and validation of a structured diagnostic psychiatric interview for DSM-IV and ICD-10. J Clin Psychiatry 59(Suppl 20): 22-33.

Shotbolt P, Tziortzi AC, Searle GE, Colasanti A, van der Aart J, Abanades $S$ et al (2012). Within-subject comparison of [(11)C]$(+)$-PHNO and [(11)C]raclopride sensitivity to acute amphetamine challenge in healthy humans. J Cereb Blood Flow Metab 32: 127-136.

Smith RC, Lay CD (1974). State and trait anxiety: an annotated bibliography. Psychol Rep 34: 519-594.

Spinks R, Nopoulos P, Ward J, Fuller R, Magnotta VA, Andreasen NC (2005). Globus pallidus volume is related to symptom severity in neuroleptic naive patients with schizophrenia. Schizophr Res 73: 229-233.

Tiffany ST, Drobes DJ (1991). The development and initial validation of a questionnaire on smoking urges. Br J Addict 86: 1467-1476.

Tsukada H, Miyasato K, Kakiuchi T, Nishiyama S, Harada N, Domino EF (2002). Comparative effects of methamphetamine and nicotine on the striatal $[(11) \mathrm{C}]$ raclopride binding in unanesthetized monkeys. Synapse 45: 207-212.

Tziortzi AC, Searle GE, Tzimopoulou S, Salinas C, Beaver JD, Jenkinson $\mathrm{M}$ et al (2011). Imaging dopamine receptors in humans with [11C]-(+)-PHNO: dissection of D3 signal and anatomy. Neuroimage 54: 264-277.

Volkow ND, Wang GJ, Fowler JS, Logan J, Gatley SJ, Wong C et al (1999). Reinforcing effects of psychostimulants in humans are associated with increases in brain dopamine and occupancy of D(2) receptors. J Pharmacol Exp Ther 291: 409-415.

Willeit M, Ginovart N, Graff A, Rusjan P, Mizrahi R, Seeman P et al (2006). In vivo competition of endogenous dopamine with the novel D2/3 receptor agonist-radioligand [11C]-(+)-PHNO. Biol Psychiatr Meeting: Toronto, ON, Canada.

Williams JM, Gandhi KK, Lu SE, Kumar S, Steinberg ML, Cottler B et al (2011). Shorter interpuff interval is associated with higher nicotine intake in smokers with schizophrenia. Drug Alcohol Depend 118: 313-319.

Wilson AA, McCormick P, Kapur S, Willeit M, Garcia A, Hussey D et al (2005). Radiosynthesis and evaluation of [11C]-(+)-4propyl-3,4,4a,5,6,10b-hexahydro-2H-naphtho[1,2-b][1,4] oxazin9 -ol as a potential radiotracer for in vivo imaging of the dopamine D2 high-affinity state with positron emission tomography. J Med Chem 48: 4153-4160. 